\title{
Social determinants of fruit and vegetable intake and validation of Pro-Children Eating Habits Questionnaire for 3 rd and 5th grade children
}

\author{
Z Dixon, F Newman, L Chapa, J Vaccaro, F Huffman
}

\section{Citation}

Z Dixon, F Newman, L Chapa, J Vaccaro, F Huffman. Social determinants of fruit and vegetable intake and validation of Pro-Children Eating Habits Questionnaire for 3rd and 5th grade children. The Internet Journal of Health. 2012 Volume 13 Number 1.

Abstract

BACKGROUND: The Pro Children Eating Habits Questionnaire has been evaluated as a valid and reliable tool in Europe to measure determinants of fruit and vegetable intake for children; however, it has not been validation for United States populations. The purpose of this study was to (1) assess the reliability and discrimination validity of fruit and vegetable correlates for the Pro Children Eating Habits Questionnaire; (2) investigate the predictive validity of determinants of fruit and vegetable consumption for multi-ethnic elementary school children; and, (3) to assess the association of social determinants with fruit and vegetable consumption.

METHODS: One hundred and thirty elementary school students from the $3^{\text {rd }}$ and $5^{\text {th }}$ grades completed this cross-sectional study.

RESULTS: Fruit and vegetable determinants, had satisfactory internal consistencies. No differences were found between the test and the retest for the individual questions with the exception of the question for mean perceived vegetable intake. The discriminatory validity indicated the questionnaire could show differences across grade and gender levels for barriers of fruit and vegetables but not for other factors. Grade together with gender explained barriers to eating fruit and vegetables. Greater availability of fruit in the home and school was associated with higher frequency of consumption. CONCLUSIONS: The results of this study indicate the Pro-Children Eating Habits Questionnaire may be a reliable and valid tool for assessing fruit and vegetable consumption of children in the United States.

\section{BACKGROUND}

The Dietary Guidelines for Americans, 2010 recommends children over 2 years of age increase their intake of fruits and vegetables. ${ }^{1}$ Despite the fact that fruits and vegetables contain essential vitamins, minerals, complex carbohydrates and dietary fiber, many children in the United States are not fulfilling their daily requirements. ${ }^{2,3}$ Krebs-Smith et al. reported that less than $20 \%$ of children are consuming five servings of fruit, and vegetables on a daily basis. ${ }^{3}$

Health behavior learned in childhood has been associated with fruit and vegetable consumption (FVC) in adulthood. Interventions to increase FVC consumption during childhood may have a lifelong impact on their quality of life. Currently, nutrition interventions have only been reasonably successful in promoting the sustained intake of adequate amounts of FVC. ${ }^{6}$ Instruments assessing FVC should include psychosocial and environmental factors contributing to diet. ${ }^{6}$ Food frequency questionnaires have been shown to be valid and reliable instrument for collecting self-reported data in children as young as eight years old. ${ }^{7-10}$ Given this rationale, the Pro Children Project designed a specific food frequency instrument to measure FVC intakes in children throughout Europe, without the assistance of administrators or parents. ${ }^{11}$

To examine psychosocial and environmental determinants of FVC consumption patterns among children, the Pro Children Project applied the Social Cognitive theory (SCT). ${ }^{12}$ The developers of the project applied SCT, which proposes that determinants of health-related behavior can be influenced by the cultural, physical, and social environment, to FVC in children. ${ }^{6}$ Few investigations regarding determinants of FVC have been conducted among children. ${ }^{12-14}$ The Pro Children Eating Habits Questionnaire dietary has been evaluated as a 
valid and reliable tool in Europe ${ }^{13}$; however, it has not been validation for United States populations. The purpose of this study was to (1) assess the reliability and discrimination validity of fruit and vegetable correlates for the Pro Children Eating Habits Questionnaire; (2) investigate the predictive validity of determinants of fruit and vegetable consumption (FVC) for multi-ethnic elementary school children in the US; and, (3) to assess the association of social determinants with fruit and vegetable consumption.

\section{METHODS}

\section{PARTICIPANTS, PROCEDURE, DESIGN}

The $3^{\text {rd }}$ and $5^{\text {th }}$ grades were chosen where reading level would be sufficient to comprehend the questionnaire and allowing enough separation of age. Of the 180 students recruited from the third $(n=77)$ and fifth $(n=103)$ grades, 130 (72.2\%) elementary school students at this medium-sized elementary school in the southeast participated. Permissions to conduct the study were obtained from the Research Committee at the County Public Schools and the Institutional Review Board (IRB) of the particular school. The designated teachers distributed consent forms to all third- and fifth-grade students. On the first day of the study, the purpose of the study was explained to the students. After all questions were answered satisfactorily, students of consenting parents/guardians were asked to sign the assent form. The researcher provided instructions on the correct way to complete the questionnaire and answered any questions. Questionnaires were collected and scanned for obvious errors such as a complete page of missing entries. Due to the constraints of the public school environment the researcher was not allowed to insist on completion of missing responses. One week later, the identical instrument was administered to the fifth-grade participants, thereby assessing the test-retest reliability of the instrument. As an incentive, each participant received a package containing a MyPyramid magnet, a Color Way Produce wheel and a pencil.

\section{INSTRUMENT: PRO CHILDREN QUESTIONNAIRE}

The Pro Children Project developed a cross-sectional questionnaire that not only assessed FVC intake, but also evaluated the determinants associated with these consumption patterns in children. ${ }^{6}$ Sections of the Pro Children Questionnaire included: (1) demographics of the students, (2) usual intake of FVC, and (3) environmental determinants affecting FVC consumption patterns.
Haraldsdottir et al. ${ }^{11}$ determined that the questionnaire was a valid and reliable instrument to determine FVC intake in European children. De Bourdeaudhuij et al. ${ }^{12}$ concluded that the questionnaire was a valid and reliable tool for evaluating personal, social, environmental and cultural factors that influence FVC consumption in European children. ${ }^{13}$ The Pro Children Questionnaire was developed as the first phase of the Pro Children Project which aimed to promote fruit and vegetable intake in European school children. A detailed discussion of the development of this questionnaire is discussed elsewhere. ${ }^{13}$ Briefly, elements from the AttitudesSocial Influence-Self-efficacy (ASE), and the Ecological models were used, as the theoretical framework, to develop categories of influence based on a literature search. The specific determinants were chosen based on outcomes from qualitative studies (interviews and focus groups comprised of school aged children) and other self-administered food questionnaires administered in classrooms.

Determinants of FVC were measured as personal, social and environmental scales using constructs based on those used by De Bourdeauhuij et al. ${ }^{13}$, and Kristjansdottir et al. ${ }^{15}$ and modified based on Kendall's tau b correlations of this study. Separate scales were used for fruit and vegetables for validation in the European populations and for this study. The choice for separate scales was in agreement with several other studies and was due to the factor analysis and distinctions in fruit and vegetable related behaviors. ${ }^{16-18}$ The collinearity of two self-efficacy measured necessitated the removal of one. We retained "If I decide to eat vegetables every day, I can do it" and removed "It is difficult for me to eat vegetables everyday" since the former was specifically personal and the latter could have been due to environmental factors. Eight logical factors, designated at $\mathrm{F}$ for fruit and $\mathrm{V}$ for vegetables, were identified analogous for fruits (F1-4) and vegetables (V1-4). Positive attitudes, liking and selfefficacy (F1, V1) and barriers F2, V2) were measured for personal determinants. Perceived active encouragement from family, family rules, and peer and parental modeling were social determinants (F3, V3). Accessibility and availability were factors for the physical environment (F4, V4). Knowledge of the recommendations FVC (separate questions for fruit and vegetable intake) was considered a separate category.

\section{DATA ANALYSIS}

Analyses were performed using all data without replacement of missing values. The factors were combined into scales 
and the internal consistency between each factor was measured by Cronbach's alpha coefficient. Multiple regression assumptions regarding normality, linearity and homoscedasticity were acceptable. Test-retest reliability of the multi-dimensional scales was assessed by repeated measure multivariate analysis of variance as opposed to multiple univariate tests (e.g., Bland/Alterman) of agreement. Fruit and vegetables consumed per day were totaled separately and together. Mean fruit and vegetable intake per day was compared by gender and grade using the Student t-test. The General Linear Model was used to assess discriminative validity. Demographics were not found to be associated with FVC. Separate regression analyses were conducted for fruit and vegetables to test an ordered set of a priori predictions to explain the variance of FVC based on the factors. Step one included demographics and knowledge, step two personal, step three, social, step 4, encouragement, and step 5, physical environment (availability and accessibility). The dependent variable for fruit consumption was 'how often do you eat fresh fruit'. Vegetable intake combined three questions asking 'how often do you eat salad, other raw vegetables and cooked vegetables'. Knowledge was considered a separate construct and possible confounder when assessing personal, social and environmental determinants. The main effects of race, gender and grade were not associated with knowledge of FVC recommendations. Three-way interactions show differences; however, the number in each category was insufficient ( $<30$ and $<10$ for African-Americans) to determine differences. Analyses were conducted using Statistical Package for Social Science (SPSS) version 18. A p-value of $<.05$ was considered significant.

\section{RESULTS}

\section{GENERAL CHARACTERISTICS}

One hundred and thirty third- and fifth-grade students participated in the study. Demographic characteristics (Table 1) showed that there were no statistically significance in the proportions of those within each gender and each ethnicity grouping between $3{ }^{\text {rd }}$ and $5^{\text {th }}$ graders. The ethnic group categories were collapse to three groups, based on the estimated marginal means (African American, Hispanic and White non-Hispanic).

\section{INTERNAL CONSISTENCY OF ITEMS WITHIN EACH FACTOR}

Table 2 presents Cronbach's Alpha for the fruit and vegetable scales. A value of 0.70 to 0.79 is considered to be acceptable, .80 to .89 to be very good and .90 and higher to be excellent. ${ }^{19}$ The developers of the Pro Children questionnaire used .50 as a cut-off for a satisfactory reliability coefficient for self-administered questionnaire for children 10-11 years of age. ${ }^{13}$ Cronbach's alpha values greater than .70 were found for all the scales except for the fruit 'availability' scale (F4) which was still in the acceptable range as stated by the developers of the questionnaire $^{13}$ and near the cut-off point (.70) recommended by Cohen. ${ }^{19}$ Cronbach's alpha values were higher for all vegetable factors except for barriers.

\section{TEST-RETEST RELIABILITY}

No differences were found between the test and the retest for the individual questions, factors, and the total means of fruits and vegetables with the exception of the question for mean perceived vegetable intake. The mean vegetable intake was lower at the retest $(\mathrm{t}=2.29, \mathrm{p}=.023)$.

\section{DISCRIMINATIVE VALIDITY}

Discriminative validity was tested via the general linear model, multivariate analysis of variance, to ascertain whether the instrument could demonstrate statistical significance differences between grade (third and fifth graders), and gender. The size of the effect was measured by the partial eta square and presented in Table 3 for each fixed effect. The discriminatory validity indicated the Pro Children Questionnaire can show differences across grade and gender levels for barriers of fruit (F2) and vegetables (V2), but not for other factors. Grade together with gender explained barriers to eating fruit and vegetables (F2).

The means for FVC per day are presented by gender and grade in Table 4. Fifth-graders compared to $3{ }^{\text {rd }}$ graders and girls compared to boys reported a higher total fruit and vegetable consumption.

Table 5 presents the ordered set of regression analyses based upon prior assumptions for fruit and vegetable determinants in the study population. Separate but parallel models were conducted for reported fruit and vegetable consumption. Knowledge of recommended FVC was a determinant of FVC, adjusting for race, gender and grade (step 1).

'Knowledge' remained significant when 'attitudes and likes' (F1 or V1) was added (step 2). 'Attitudes and likes' (F1, V1) were significant with knowledge in the model. 'Barriers' were not associated with FVC and 'knowledge' was no longer significant with the addition of 'barriers' (F2, V2, step 3). 'Attitudes and likes' remained significant in the fruit 
model but not in the vegetable model with the addition of 'barriers'. 'Encouragement' (F3, V3, step 4) was not associated with FVC. 'Attitudes and likes' became significant for the fruit model with the addition of F3. Third graders were associated with lower fruit consumption as compared to $5^{\text {th }}$ graders, adjusting for race, 'knowledge', 'attitudes and likes', 'barriers' and 'encouragement'. 'Availability' (F4) and 'attitudes and likes' (F3) were determinants for fruit intake, adjusting for race, gender, grade, 'knowledge', and 'encouragement'.

\section{Figure 1}

Table 1. Demographics of the Study Population

\begin{tabular}{|c|c|c|c|c|c|c|c|c|c|c|}
\hline \multicolumn{2}{|c|}{ Grade } & \multicolumn{2}{|c|}{ Gender } & \multicolumn{7}{|c|}{ Ethnicity } \\
\hline Tim & & Girls & Boys & $\begin{array}{l}\text { Hikpanic' } \\
\text { Latino }\end{array}$ & $\begin{array}{l}\text { Afrikan } \\
\text { Amerisan }\end{array}$ & White & $\begin{array}{l}\text { American } \\
\text { Indian } \\
\text { Alaska } \\
\text { Native } \\
\text { Asian }\end{array}$ & $\begin{array}{l}\text { Native } \\
\text { Hawaian } \\
\text { or other } \\
\text { Pacific } \\
\text { Llander }\end{array}$ & $\begin{array}{l}\text { Oeterf } / \\
\text { Unknown }\end{array}$ & $\begin{array}{l}\text { No } \\
\text { Resposes }\end{array}$ \\
\hline $3^{\text {rt }}$ & . & 24 & 33 & 23 & 12 & 14 & 1 & 0 & 7 & 0 \\
\hline$s^{a}$ & $1^{*}$ & 45 & 28 & 48 & 7 & 9 & 3 & 0 & 3 & 3 \\
\hline $5^{\mathrm{an}}$ & $2^{n e}$ & 41 & 23 & 42 & 7 & 7 & 3 & 0 & 2 & 3 \\
\hline
\end{tabular}

\section{Figure 2}

Table 2. Reliabilities for Fruit and Vegetable Factors

\begin{tabular}{|c|c|c|c|c|}
\hline Scale & Items & $\mathrm{N}$ & Mean(SD) & $\begin{array}{l}\text { Cronbach's } \\
\text { Alpha }\end{array}$ \\
\hline F1- Attitudes and liking, fruit & 4 & 126 & $7.03(3.4)$ & .751 \\
\hline F2- Barriers, fruit & 9 & 104 & $38.8(8.9)$ & 906 \\
\hline $\begin{array}{l}\text { F3- Active parental encourageneren, modeling (peer, } \\
\text { parent) and family rule, fruit }\end{array}$ & 8 & 112 & $18.2(6.4)$ & .710 \\
\hline $\begin{array}{l}\text { F-4-Availability at home, school and outside activities, } \\
\text { fruit }\end{array}$ & 7 & 119 & $17.1(5.6)$ & .672 \\
\hline V1-Attitudes, liking and self-efficacy, vegetables & 6 & 103 & $13.7(6.6)$ & 876 \\
\hline V2-Barriers, vegetables & 9 & 100 & $35.9(12.0)$ & 956 \\
\hline $\begin{array}{l}\text { V3- Active parental encouragement, modeling (peer, } \\
\text { parent), and family rule }\end{array}$ & 9 & 105 & $20.9(8.1)$ & .797 \\
\hline $\begin{array}{l}\text { V4-Availablility at bome, school and outside activities, } \\
\text { vegetables }\end{array}$ & 7 & 109 & $19.6(7.3)$ & $\$ 17$ \\
\hline
\end{tabular}
Note: range 5 poirk scale from $1=$ "fully agree" to $5=$ "fully disagree" or from $1=$ "yes, always" to $5=$ "no,

\section{Figure 3}

Table 3. Discrimination validity of fruit and vegetable factors by grade and gender

\begin{tabular}{|l|l|l|l|}
\hline Source & $\begin{array}{l}\text { Dependent } \\
\text { Variables }\end{array}$ & $\begin{array}{l}\text { Partial } \\
\text { 12 }\end{array}$ & p-value \\
\hline Grade & F1 & .009 & .398 \\
\hline & F2 & .119 & .001 \\
\hline & F3 & .023 & .163 \\
\hline & F4 & .025 & .152 \\
\hline & F1 & .004 & .584 \\
\hline Gender & F2 & .217 & .001 \\
\hline & F3 & .044 & .053 \\
\hline & F4 & .030 & .110 \\
\hline & F1 & .016 & .255 \\
\hline Grade by gender & F2 & .105 & .002 \\
\hline & F3 & $<.001$ & .987 \\
\hline & F4 & $<.001$ & .981 \\
\hline & V1 & .024 & .175 \\
\hline Grade & V2 & .043 & .067 \\
\hline & V3 & .044 & .064 \\
\hline & V4 & $<.001$ & .934 \\
\hline & & & \\
\hline & V1 & .005 & .529 \\
\hline Gender & V2 & .165 & $<.001$ \\
\hline & V3 & $<.001$ & .972 \\
\hline & V4 & 0.014 & 0.309 \\
\hline & V1 & .002 & .665 \\
\hline Grade by gender & V1 & .060 & .030 \\
\hline & V2 & .003 & .612 \\
\hline & V3 & .020 & .218 \\
\hline & V4 & \\
\hline
\end{tabular}

Notes: F-fruit factor, V-Vegetable factors. Numbers denote categories for both fruit and vegetable factor: 1= Personal attitude, liking, seff-efficacy, 2-perceived barriers 3- active encouragement, modeling, family ule; 4 -accessibility and availability.

\section{Figure 4}

Table 4. Mean fruit and vegetable consumption by gender and grade

\begin{tabular}{|c|c|c|c|c|}
\hline Variable & Category & $N$ & Mean (SD) & p-value \\
\hline \multirow[t]{4}{*}{ Total fruit and vegetable/day } & girl & 69 & $3.00(.36)$ & .129 \\
\hline & boy & 61 & $2.88(.50)$ & \\
\hline & $3^{n}$ grade & 57 & $2.85(.50)$ & .030 \\
\hline & $5^{\text {th }}$ grade & 73 & $3.02(.36)$ & \\
\hline \multirow[t]{4}{*}{ Total fruit/day } & girl & 69 & $2.89(0.29)$ & .244 \\
\hline & boy & 61 & $2.81(.49)$ & \\
\hline & $3^{n}$ grade & 57 & $2.77(.49)$ & .046 \\
\hline & $5^{\text {th }}$ grade & 73 & $292(.28)$ & \\
\hline \multirow[t]{4}{*}{ Total vegetable/day } & girl & 69 & $3.11(.56)$ & .208 \\
\hline & boy & 56 & $2.93(.68)$ & \\
\hline & $3^{n}$ grade & 53 & $2.92(.68)$ & .079 \\
\hline & $5^{\text {th }}$ grade & 72 & $3.13(.56)$ & \\
\hline
\end{tabular}




\section{Figure 5}

Table 5. Regression models for factors of fruit and vegetable intake adjusting for knowledge of fruit and vegetable recommendations

\begin{tabular}{|c|c|c|c|c|c|c|c|c|c|c|}
\hline \multicolumn{11}{|c|}{ Dependent variable: Fruit intake: "How often do you usually eat fresh fruit?" } \\
\hline \multirow{2}{*}{ rV } & & \multicolumn{2}{|c|}{ step 2} & \multicolumn{2}{|c|}{$\operatorname{step} 3$} & \multicolumn{2}{|c|}{ step 4} & \multicolumn{2}{|c|}{ step 5} \\
\hline & & $\mathrm{p}$ & B & $\mathrm{p}$ & B & 0 & B & $\mathrm{p}$ & B & $\mathrm{p}$ \\
\hline \multicolumn{11}{|l|}{ Demographics } \\
\hline $3^{n}$ Grade & .54 & .146 & -.52 & .140 & -.78 & .054 &. .88 & .045 &. .55 & .221 \\
\hline Male & & 65 & .02 & .963 & .003 & 994 & .03 & .940 & .14 & .752 \\
\hline tspan & -.49 & .223 & -.40 & 1 & & & 17 & .102 & -.63 & 187 \\
\hline frican Am & .19 & 35 & .69 & 10 & & & .98 & 49 & 93 & .201 \\
\hline Knowle & .24 & .001 & .21 & .004 & .12 & & .15 & .074 & .10 & .300 \\
\hline \multicolumn{3}{|c|}{ F1-attitudes and likes } & .19 & $\leq 0$ & .21 & & .21 & & .22 & .005 \\
\hline \multicolumn{3}{|c|}{ F2-baniers } & & & .001 & & .03 & 290 & .03 & 232 \\
\hline \multirow{2}{*}{\multicolumn{4}{|c|}{$\begin{array}{l}\text { F3- encourage, model, rules } \\
\text { F4- available, home, school, activity }\end{array}$}} & & & & .02 & .652 & .03 & .549 \\
\hline & & & & & & & & & .10 & .047 \\
\hline \multicolumn{3}{|c|}{$\begin{array}{l}\text { Model 1: } \\
F(5,121)=3.03 \\
P=.013 \\
\text { Adj. } R^{2}=.074\end{array}$} & \multicolumn{2}{|c|}{$\begin{array}{l}\text { Model 2: } \\
\text { F }(6,117)=5.50 \\
p<.001 \\
\text { Ad. } R^{2}=.180\end{array}$} & \multicolumn{2}{|c|}{$\begin{array}{l}\text { Modd 3: } \\
\mathrm{F}(7,93)-3.76 \\
\mathrm{P}=.001 \\
\text { Adj. } \mathrm{R}^{2}=.162\end{array}$} & \multicolumn{2}{|c|}{$\begin{array}{l}\text { Mode 4: } \\
F(8,83)-3.37 \\
p=, 002 \\
\text { Adj. } R^{2}=.172\end{array}$} & \multicolumn{2}{|c|}{$\begin{array}{l}\text { Model } 5: \\
\mathrm{F}(9,77)-3.19 \\
\mathrm{p}=.003 \\
\text { Adj. } \mathrm{R}^{2}=.186\end{array}$} \\
\hline \multicolumn{11}{|c|}{$\begin{array}{l}\text { Dependent variable: Vegetable intake; composite for "How often do you usually eat 1) salad or grated } \\
\text { vegetables, 2) other raw vegetables, 3) cooked vegetables?' }\end{array}$} \\
\hline \multirow[b]{2}{*}{ IV } & \multicolumn{2}{|c|}{ step 1} & \multicolumn{2}{|c|}{ step 2} & \multicolumn{2}{|c|}{ step 3} & \multicolumn{2}{|c|}{ step 4} & \multicolumn{2}{|c|}{ step 5} \\
\hline & B & p & B & p & B & 0 & B & $\mathbf{p}$ & B & $p$ \\
\hline \multicolumn{11}{|l|}{ Demographics } \\
\hline $3^{n}$ Grade & -.22 & & .16 & .8 & 9 & & .5 & .668 & .83 & .503 \\
\hline Male & & & 1.16 &. & .7 & & .81 & 0 & .95 & .419 \\
\hline & & & & & & & & & & .954 \\
\hline & -.77 & & -2.00 & & & & & & & .675 \\
\hline Knowledge & .74 & $<.001$ & .45 & & & & & & 8 & .447 \\
\hline \multicolumn{3}{|c|}{ V1 -attitudes and likes } & .27 & $<$. & & & & & .10 & .456 \\
\hline \multirow{2}{*}{\multicolumn{3}{|c|}{$\mathrm{V} 2$ - barriers }} & & & -.04 & & -0 & 1 & - .08 & .114 \\
\hline & & & & & & & .10 & 191 & .07 & .411 \\
\hline \multicolumn{5}{|c|}{ V4- available, bome, school, activity } & & & & & .13 & \\
\hline \multirow{2}{*}{\multicolumn{3}{|c|}{$\begin{array}{l}\text { Model 1: } \\
\mathrm{F}(5,116)=3.40 \\
\mathrm{p}=.007 \\
\text { Adj. } \mathrm{R}^{2}=.095\end{array}$}} & \multirow{2}{*}{\multicolumn{2}{|c|}{$\begin{array}{l}\text { Model 2: } \\
\text { F }(6,91)=4.36 \\
\text { p- }-.001\end{array}$}} & $\begin{array}{l}\text { Model 3: } \\
\text { F } 7,77) \\
\text { p- }-.001\end{array}$ & $=4.07$ & $\begin{array}{l}\text { Model 4: } \\
\text { F }(8,69) \\
\text { p- .002 }\end{array}$ & & $\begin{array}{l}\text { Model } \\
F(9,6 \\
p-.00\end{array}$ & $\begin{array}{l}5: \\
5)=2.86 \\
77\end{array}$ \\
\hline & & & & & & & Adj. $R^{2}=$ & .202 & Adi. $R^{2}$ & $2=.184$ \\
\hline
\end{tabular}

\section{DISCUSSION}

In the present study, the validity and reliability of the Pro Children food frequency questionnaire for measuring determinants of fruit, and vegetable consumption were investigated among third and fifth graders in BLIND FOR REVIEW. The study revealed that the Pro Children Questionnaire is a reliable instrument over a period of time and has moderate to good internal consistency for the scales, with the exception of one factor on the availability of fruit which was fair (Crombach's alpha = .672). The

discriminative validity of the constructs was acceptable only for barriers for fruits and vegetables, showing differences between $3{ }^{\text {rd }}$ and $5^{\text {th }}$ graders and by gender. Ideally, determinant scales would show measurement invariance across gender, grade and ethnicity; however, generalization to diverse demographic groups may not be realistic. Geller and Dzewaltowski ${ }^{20}$ found fruit and vegetable scales for self-efficacy and proxy self-efficacy (belief that they could get an adult to act on their behalf) in $4^{\text {th }}-6^{\text {th }}$ grade children $(\mathrm{N}=232)$ to be invariant across ethnicity, gender and parent's socioeconomic status. Consumption of fruit and vegetable intake in this study was associated with a complex mutual influence of personal, social and environmental factors accounting for approximately $20 \%$ of the variance.
Since demographic differences were found by discriminatory analysis, analyses were adjusted for grade, gender and race.

Psychosocial factors, such as food preference, knowledge, attitudes, and self-efficacy have been associated with FVC. ${ }^{6}$ We found positive attitudes towards fruit and vegetables to be associated with consumption in accordance with several studies. ${ }^{12,14,21}$ However, barriers and FVC were not associated in our study. Barriers (dislikes) were negatively associated with vegetable intake for $(\mathrm{N}=3534)$ randomly sampled Spanish children aged 2-24 years from the enKid study. ${ }^{22}$ Several studies suggest that taste preference explains a relatively low percent variance $(<15 \%)$ of the determinants contributing to FVC consumption ${ }^{12,14,21}$, suggesting other factors are involved. Knowledge was found to mediate FVC for a school-based nutrition intervention in $4^{\text {th }}$ grade children from Alabama ( $\mathrm{N}=1584)$, accounting for approximately $10 \%$ of the intervention effect. ${ }^{23}$ Another personal factor that has been positively associated with FVC in children is self-efficacy. ${ }^{21,24,25}$ In these analyses, selfefficacy was incorporated with 'attitudes and likes' and was associated with FVC until 'encouragement, role model and parental rules' was added.

Preferences may be confounded not only with knowledge but with social and environmental determinants such as encouragement and access in determining FVC. Eating is, in part, a social activity and eating behavior is influence by the child's perceived parental and peer role modeling, parenting styles and encouragement ${ }^{11,26-29}$ and availability. ${ }^{30}$ Physical environmental factors include the availability and accessibility of FVC in both the home and at school. For this study, proxy self-efficacy was a part of the 'availability' scale. The 'availability' and 'attitudes and likes' scales were associated with fruit intake and together with the other scales and demographics explained $18.6 \%$ of the variance of fruit intake. Our results for fruit concur with several studies reporting the availability and accessibility of FVC were significantly associated with determining FVC intake in children. ${ }^{14,26,27,31}$ Availability and accessibility accounted for more than $10 \%$ of the variability in FVC consumption. ${ }^{14}$

Bere and Klepp ${ }^{24}$ found that changes in accessibility at home and school from baseline to follow-up explained part of the variance of dietary intake. Parents primarily control FVC availability in the home, which in turn affects the development of children's food preference. ${ }^{27}$ In addition to parental influence, the availability and accessibility of FVC as well as food opportunities in schools determine a child's 
FVC consumption. ${ }^{32-34}$

Children receiving no intervention with high baseline accessibility, changes in fruit and vegetable preferences were associated with larger changes in intake than their counterparts with low baseline accessibility. ${ }^{36}$ Accessibility could mediate the relationship of preferences and FVC. Another possible mediator between preferences and intake is parenting consumption (modeling). In a Belgian study of preschool children from 46 schools $(\mathrm{N}=755)$, parental modeling (FVC) negated the association of parenting style (positive interactions, laxness and overactivity). ${ }^{29}$

\section{LIMITATIONS}

Convenience samples, and not representative samples, were used. All data were self reported and thereby subject to possible comprehension, memory and recording bias. The questionnaires were completed in classroom settings and the students may have been distracted by their peers. There were missing values for each determinant and this may introduce non-response bias. For the hierarchical regressions, two- and three-way interactions could not be tested due to insufficient power to determine a difference (less than 30 participants per category).The selected elementary school offered nutrition education to all of its students. Students from Time 1 to Time 2 were not paired for comparisons; however, reliability was established by the mean responses. This study did not adjust for socioeconomic factors. Children in singleparent households were less likely to consume FVC as compared to children in two-parent households (53\% vs. $61 \%) .{ }^{32}$ Educational level and employment status were also identified as determinants of FVC consumption. ${ }^{36}$

\section{CONCLUSION}

Despite the fact that incorporating FVC in one's daily diet is pivotal in current and future health of children, FVC intakes are low. ${ }^{2,3}$ As the Pro Children Questionnaire may be a reliable and valid tool for assessing fruit and vegetable consumption of children in the United States in a multiethnic, elementary school population, future studies are warranted to confirm our results. Future research is required to validate this questionnaire for other US populations and to determine differences by grade, ethnicity and other sociodemographic factors. Future studies investigating the influences of personal, social and environmental factors on a child's intake of FVC are necessary for tailoring interventions to meet diverse needs.

\section{IMPLICATIONS FOR SCHOOL HEALTH}

Although this study examined determinants of FVC in a diverse county in the United States, the implications for school health are much broader than for this single county. If the findings that providing fruit in the school increases fruit consumption independent of likes and dislikes, then the solution may be to substitute most desserts with raw and cooked fruit. Increasing vegetable consumption may be more challenging than increasing fruit consumption. The problem of vegetable consumption among elementary school children may be due to exposure. The experiences of tasting vegetables may have been negative and programs should aim to increase 'liking' of a wide variety of vegetable with different preparations.

These findings suggest the need to probe into the aspects of vegetables that make them appealing as well as what makes them unappealing through qualitative analysis. Another approach stemming from these results would be to design intervention studies. School educators should understand that many of the determinants of FVC are modifiable and within their jurisdiction to influence. School educators can directly guide FVC by providing availability to fruits and vegetables for lunches and at afterschool programs. Demonstrations during school time and afterschool involving parents in food preparation could be another means of encouraging FVC. Demonstration for convenient and tasty recipes involving raw and cooked fruits and vegetables should also include tasting the foods. This type of intervention can motivate and enable families to increase FVC.

To date, there are limited assessments of FVC determinants of school children, particularly in the United States. Yet, understanding these determinants is vital in changing/directing them toward increasing FVC. Paying attention to the barriers and enablers of FVC by survey or interview methods is essential in directing school health policies. Results from the last School Health Policies and Programs Study 2006 conducted by the Centers for Disease Control and Prevention revealed that even schools that sold healthy (high nutrition density, low sugar, low fat) foods and beverages also sold high fat, sodium and sugar foods and beverages. ${ }^{37}$ New or amended policies that incorporate strategies to increase FVC and eliminate the opportunities for unhealthy food choices are needed to counteract the obesity epidemic. 


\section{References}

1. U.S. Department of Agriculture and U.S. Department of Health and Human Services: Dietary Guidelines for Americans, 2010. 7th Edition, Washington, DC: U.S.

Government Printing Office, December;2010.

2. Munoz KA, Krebs-Smith SM, Ballard-Barbash R,

Cleveland LE. Food Intakes of US Children and Adolescents Compared with Recommendations. Pediatrics. 1997;100 (3

Pt 1): 323-329.

3. Krebs-Smith SM, Cook A, Subar AF, Cleveland L, Friday

J, Kahle LL. Fruit and Vegetable Intakes of Children and

Adolescents in the United States. Arch Pediatr Adolesc Med.

1996;150(1): 81-86.

4. Mikkila V, Rasanen L, Raitakari OT, Pietinen P, Viikari J. Longitudinal Changes in Diet from Childhood into

Adulthood with Respect to Risk of Cardiovascular Diseases:

The Cardiovascular Risk in Young Finns Study. Eur J Clin

Nutr. 2004;58: 1038-1045.

5. Kelder SH, Perry CL, Klepp K-I, Lytle L. Longitudinal

Tracking of Adolescent Smoking, Physical Activity and

Food Choice Behaviors. Am J Public Health. 1994;84(7):

1121-1126.

6. Klepp K-I, Pérez-Rodrigo C, De Bourdeaudhuij I, Due

PP, Elmadfa I, Haraldsdóttir J, Konig J, Sjostrom M,

Thórsdóttir I, Vaz de Almeida MD, Yngve A, Brug J.

Promoting Fruit and Vegetable Consumption among

European Schoolchildren: Rationale, Conceptualization and

Design of the Pro Children Project. Ann Nutr Metab.

2005;49:212-220.

7. Baranowski T, Dworkin R, Henske JC, Clearman DR,

Dunn JK, Nader PR, Hooks PC. The Accuracy of Children's

Self-Reports of Diet: Family Health Project. J Am Diet

Assoc 1986;86(10):1381-1385.

8. Lytle L, Nichaman, Milton Z, Obarzanek E, Glovski E,

Montgomery D, Nicklas T, Zive M, Feldman H. Validation

of 24-Hour Recalls Assisted by Food Records in Third-

Grade Children. J Am Diet Assoc. 1993;93(12):1431-1436.

9. Livingstone MBE, Robson PJ. Measurement of Dietary

Intake in Children. Proc Nutr Soc. 2000;59(2):279-293.

10. Baranowski T, Domel SB. A Cognitive Model of

Children's Reporting of Food Intake. Am J Clin Nutr.

1994;59 (Suppl): 212S-217S.

11. Haraldsdóttir J, Thórsdóttir I, de Almeida MD, Maes L,

Pérez Rodrigo C, Elmadfa I, Frost Andersen L. Validity and

Reproducibility of a Precoded Questionnaire to Assess Fruit

and Vegetable Intake in European 11- to 12-Year-Old

Schoolchildren. Ann Nutr Metab. 2005; 49(4): 221-227.

12. Resnicow K, Davis-Hearn M, Smith M, Baranowski T,

Lin L, Baranowski J, Doyle C, Wang D. Social-Cognitive

Predictors of Fruit and Vegetable Intake in Children. Health

Psychol. 1997;16(3): 272-276.

13. De Bourdeaudhuij I, Klepp KI, Due P, Rodrigo CP, de

Almeida M, Wind M, Krølner R, Sandvik C, Brug J.

Reliability and Validity of a Questionnaire to Measure

Personal, Social and Environmental Correlates of Fruit and

Vegetable Intake in 10-11-Year-Old Children in Five

European Countries. Public Health Nutr. 2004;8(2):

189-200.

14. Cullen KW, Baranowski T, Owens E, Marsh T,

Rittenberry L, de Moor C. Availability, Accessibility, and

Preference for Fruit, 100\% Fruit Juice, and Vegetables

Influence Children's Dietary Behavior. Health Educ Beh.

2003;30(5): 615-626.

15. Kristjansdottir AG, Thorsdottir I, De Bourdeaudhuij I,

Due P, Wind M, Klepp K-I. Determinants of fruit and

vegetable intake among 11-year-old schoolchildren in a country of traditionally low fruit and vegetable consumption. Int J Behav Nutr Phys Act. 2006;3:41

doi:10.1186/1479-5868-3-41.

16. Geller KS, Dzewaltowski DA, Rosenkranz RR,

Karteroliotis K. Measuring children's self-efficacy and proxy efficacy related to fruit and vegetable consumption. J Sch Health. 2009;79:51-57.

17. Reinaerts E, Nooijer J, Candel M, Vries N. Explaining school children's fruit and vegetable consumption the contributions of availability, accessibility, exposure, parental consumption and habit in addition to psychosocial factors.

Appetite. 2006;48:248-258.

18. Vereecken C, Van CDamme W, Maes L. Measuring attitudes, self-efficacy, and social and environmental influences on fruit and vegetable consumption of 11- and 12year- old children: reliability and validity. J. Am Diet Assoc. 2005;105(2):257-261.

19. Cohen, J. Statistical Power Analysis for the Behavioral Sciences, 2nd edition. Hillsdale, NJ: Lawrence Erlbaum Associates; 1988.

20. Geller KS, Dzewaltowski DA. Examining elementary school-aged children's self-efficacy and proxy efficacy for fruit and vegetable consumption. Health Educ Behav. 2010;37(4):465-478.

21. Domel SB, Thompson WO, Davis HC, Baranowski T, Leonard SB, Baranowski . Psychosocial Predictors of Fruit and Vegetable Consumption among Elementary School Children. Health Educ Res.1996;11(3): 299-308.

22. Perez-Rodrigo C, Ribas L, Serra-Majem L, Aranceta J. Food Preferences of Spanish Children and Young People: the enKid Study. Eur J Clin Nutr. 2003;57 Suppl 1: S45-48. 23. Reynolds KD, Bishop DB, Chou C-P, Xie B, Nebeling L, Perry CL. Contrasting Mediating Variables in Two 5-ADay Nutrition Intervention Programs. Prev Med. 2004;39(5): 882-893.

24. Bere E, Klepp K-I. Correlates of Fruit and Vegetable Intake Among Norwegian Schoolchildren: Parental and SelfReports. Public Health Nutr. 2004;7(8): 991-998.

25. Cusatis DC, Shannon BM. Influences on Adolescent Eating Behavior. J Adolesc Health. 1996;18(1): 27-34. 26. Cullen KW, Baranowski T, Rittenberry L, Cosart C, Hebert D, de Moor C. Child-reported Family and Peer Influences on Fruit, Juice and Vegetable Consumption: Reliability and Validity of Measures. Health Educ Res. 2001;16(2):187-200.

27. Skinner JD, Carruth BR, Bounds W, Ziegler PJ: Children's Food Preferences: A Longitudinal Analysis. J Am Diet Assoc. 2002;102(11):1638-1647.

28. Vanhala ML, Laitinen J, Kaikkonen K, Keinänen Kiukaanniemi S, Korpelainen R. Parental predictors of fruit and vegetable consumption in treatment-seeking overweight children. J Human Nutr Diet 2011;24:47-53.

29. Vereecken C, Rovner A, Maes L. Associations of parenting styles, parental feeding practices and child characteristics with young children's fruit and vegetable consumption. Appetite. 2011;55:589-596.

30. Di Noia J, Contento IR. Fruit and vegetable availability enables adolescent consumption that exceeds national average. Nutr Res. 2010; 30:396-402.

31. Kratt P, Reynolds K, Shewchuk R. The Role of Availability as a Moderator of Family Fruit and Vegetable Consumption. Health Educ Behav. 2000; 27(4): 471-482. 32. Wolfe WS, Campbell CC. Food Pattern, Diet Quality, and Related Characteristics of Schoolchildren in New York State. J Am Diet Assoc. 1993;93(11): 1280-1284.

33. Cullen KW, Eagan J, Baranowski T, Owens E, de Moor C. Effect of a la carte and Snack Bar Foods at School on 
Children's lunchtime Intake of Fruits and Vegetables. J Am Diet Assoc. 2000;100: 1482-1486.

34. Kubik MY, Lytle LA, Hannan PJ, Stat M, Perry CL, Story M. The Association of the School Food Environment with Dietary Behaviors of Young Adolescents. Am J Public Health. 2003;93: 1168-1173.

35. Roos EB, Hirvonen T, Mikkila V, Karvonen S, Rimpela M. Household Educational Level as a Determinant of

Consumption of Raw Vegetables among Male and Female
Adolescents. Prev Med. 2001;33: 282-291.

36. Bere F, Klepp K-I. Changes in accessibility and preferences predict children's future fruit and vegetable intake. Int J Behav Nutr Phys Act. 2005;2:15, doi:10.1186/1479-5868-2-15.

37. O'Toole TP, Anderson S, Miller C, Guthrie J. Nutrition services and foods and beverages available at school: results from the School Health Policies and Programs study 2006. J Sch Health. 2007;77:500-521. 


\section{Author Information}

\section{Zisca Dixon, PhD}

Associate Professor, Department of Dietetics and Nutrition 11200 SW 8th Street MMC AHC-1 Room 443 Miami, Florida 33199

\section{Frederick L. Newman, PhD}

Professor Emeritus, Health Policy \& Management, Robert Stempel College of Public Health \& Social Work Florida International University

\section{Lacey Chapa, MS, RD}

Registered Dietitian, South Miami Hospital

Joan A. Vaccaro, PhD, DPD

Postdoctoral Research, Department of Dietetics and Nutrition Florida International University

Fatma G. Huffman, PhD, RD

Department of Dietetics and Nutrition Florida International University 